\section{Acknowledgements}

We thank M. E. Dewey of the Liverpool University Department of Psychiatry for his statistical advice.

\section{References}

GOLDBERG, D. (1982) The concept of a 'case' in general practice. Social Psychiatry, 17, 61-65.
JoHnson, D. A. W. (1973) An analysis of outpatient services. British Journal of Psychiatry, 122, 301-306.

Kessel, W. I. N. \& Hassall, C. (1965) Psychiatric outpatients in Plymouth - an area service analysed. British Journal of Psychiatry, 111, 10.

MoORE, A. T. \& Roland, M. O. (1989) How much variation in referral rates among general practitioners is due to chance? British Medical Journal, 298, 500-502.

WILKINSON, G. (1989) Referrals from general practitioners to psychiatrists and paramedical mental health professionals. British Journal of Psychiatry, 154, 72-76.

\title{
Writing to the patient
}

\section{Comments of patients who received a letter following an initial psychiatric out-patient consultation}

\author{
John S. Price, Consultant Psychiatrist, Milton Keynes General Hospital, \\ Milton Keynes MK6 5LD; and RaCHEL AsCH, Teaching Fellow, Applied \\ Psychology Unit, College of Aeronautics, Cranfield Institute of Technology, \\ Cranfield, Bedfordshire
}

In a recent study we compared writing to the patient with writing to the general practitioner after an initial psychiatric out-patient consultation. One of us (R.A.) interviewed the patients at home about two weeks after the consultation, and compared the two groups on satisfaction with the consultation, comprehension of information given by the psychiatrist, and compliance with advice. We felt that the comments of the patients might be of interest, particularly to those who might have considered (or done) something similar.

\section{The study}

Patients were recruited for the project from 1 July 1988 to 30 June 1989 . They were referrals by GPs to a psychiatric out-patient clinic in a District General Hospital, manned by a consultant and variably one or two SHOs/registrars (some of whom were on psychiatric and some on general practice rotations).

Patients were seen by the registrar for an hour, then presented to the consultant (usually with the patient present) for about 15 minutes, following which the consultant interviewed the patient for about 15 minutes. A few patients were seen only by the consultant. Neither registrar nor consultant knew until the end of the consultation whether the patient was in the experimental or control group, and it was at that stage that the patient was told about the research. The registrars were instructed to summarise the consultation in their letters to the patient; no format or headings were used; the letters were not checked by the consultant before dispatch.

Patients were interviewed by the research worker at home, and it was pointed out that the interviewer was independent and not connected to the hospital or the psychiatric service. In the section of the interview devoted to the letter, the patients were asked two open-ended questions, "How did you feel about getting the letter?" and, "Did you find the letter useful?" Their replies were recorded, and then they were asked to rate their feelings about the letter and its usefulness on five-point scales.

\section{Findings}

Appointments were sent to 168 patients. Ten rang to cancel or postpone. Thirty-seven did not attend. Of 
those who attended, 48 were not entered in the trial: 10 were referred to the day hospital, 15 required more intensive out-patient follow-up, 16 were unsuitable because of poor English, illiteracy, etc.; two refused to participate and five were excluded because the material was considered too sensitive.

Most of the patients were suffering from depressive, anxiety, or psychosomatic disorders. Only two had schizophrenia, and these did not do well with the letter. There were very few alcoholics as GPs are encouraged to refer them to our non-medical alcohol treatment centre. There were no acute cases as these are normally seen on domiciliary visits; the average delay between referral and consultation was three weeks.

Letters had been received by 23 patients at the time of the assessment interview. The length of the letters was between one and two sheets of A4. The letters contained roughly the same information as a letter to the GP, except that there was more 'reflection back' of the patient's problem and more integration of the problem with the patient's circumstances and with strengths and weaknesses in his personality. A copy of the letter was sent to the GP with a covering letter. These covering letters contained no information not contained in the letter to the patient; they were added as a courtesy, and they summarised the proposed treatment and follow-up arrangements for the general practitioner's convenience.

\section{Comments by the patients}

The following are the patients' replies to questions asked about how they felt about getting the letter and how useful they found it. (Key: Numbers commencing with 0 denote patient number. Numbers in parentheses after patient number denote how pleased patient was to receive the letter; i.e. $1=$ very pleased, $2=$ quite pleased, $3=$ indifferent, $4=$ not very pleased, $5=$ not at all pleased, $6=$ not sure or mixed feelings. Numbers in parentheses after USEFUL denote how useful patient found the letter; i.e., $1=$ very, $2=$ quite, $3=$ not sure, $4=$ not very, $5=$ not at all.)

Replies to the question, "How did you feel about getting the letter?" are given first, after the patient's serial number. Replies to the question, "How useful did you find the letter?" are given after "USEFUL".

002(1) I thought I'd misunderstood that I'd get a letter - it usually goes to the GP - it was great when I did get it. It showed he thought I was $\mathrm{OK}$ - and that I wasn't just being processed through the system. USEFUL(2): in the sense that he'd bothered to write to me he had acknowledged me as an individual-it didn't really enlighten me but did help to recall the interview.

004(2) It did have the facts down as I'd told them. USEFUL(5): no further comment.
005(3) It didn't really tell me anything I didn't know, it felt a bit like 'This is Your Life'. USEFUL(4): nothing new in it.

006(2) There's confirmation in black and white of what went on - a real record, not just in my mind. USEFUL(1): I could look at it and refer back to it whenever I want to - it was very pleasantly put and made me feel reassured. I don't have to just rely on my memory and it's nice to hear you're not going potty.

008(1) Reassurance that there's nothing really serious wrong with me.

USEFUL(1): I can show my husband the letter and let him really know what it's all about - perhaps the fact that it's all there in black and white makes it proper somehow.

012(1) It enables you to refer back to the consultation.

USEFUL(1): as a memory aid-very useful over a longer time - if you get more letters like this you could monitor how you're progressing. It would be very interesting for someone to be able to chart where they're going.

013(3) It didn't change anything. USEFUL(3): - only received it this morning, bit soon to tell.

015(1) Confirmed all we discussed, reminded me of what went on and showed how much he cared to bother to write the letter.

USEFUL(2): as a reminder, plus he must think I'm alright to write to me.

020(2) Gives a good record of what happened.

USEFUL(2): as a record.

021(1) If you get a letter like this and there's anything wrong you can easily pinpoint it and get it put right or clarified if necessary. That way you don't get mistakes in the notes. So, it's a good idea to write direct to the patient and it shows that they do care about you.

USEFUL(1): my wife wasn't there, the letter prompts my memory of what went on and it is always there for her and other people involved to see at any time. It must save doctors' time too in the long run - my GP had a copy of my letter and so we could discuss things more easily.

022(2) It showed that I'd been able to talk and it was nice to be recognised as an individual and not just another case number.

USEFUL(2): as I read the letter it was all there as I had spoken it - it boils down to a relief that I was sure that I had been able to speak to someone about how I really felt.

023(1) I thought it was an excellent idea - I wish all doctors would do it. Too often patients are disregarded as soon as they leave the room. 
USEFUL(2): there were some things he'd got wrong but knowing that will save me from going back thinking he's got it all right when he hasn't and I can make sure they get put right.

026(1) It does show that he did take it all in - a very personal touch - very good to show that someone does care.

USEFUL(1): made it all very clear and condensed the problem down.

029(1) It was very useful and unusual to get anything like this from doctors - they often treat you like fools.

USEFUL(1): for my wife to see.

030(1) It showed they listened and wanted to provide a good service - obviously really cared about the patient to write direct to them.

USEFUL(4): not very useful, doesn't give insight, just objective account of what went on.

032(1) Seemed very nice and showed he had really listened to me-just hope he can do something to help.

USEFUL(3): not sure - it might be, but lovely thing to get.

036(1) Nice to be able to read it as well as talk about it - can go over it as many times as I need to. USEFUL(1): just to go over it all again.

038(1) So nice that he hasn't just written to the GP but also to me. Identical letters so I knew exactly what the GP has been told.

USEFUL(1): to read through and see that he seemed to understand just what my problems were.

042(1) I liked to be able to read over what I'd said to him and what he'd said to me. Nice to refresh my memory.

USEFUL(3): just as a refresher to memory.

044(1) When I read it it made me understand that he really did understand. My husband said he'd summed me up to a ' $t$ '. Also, very unusual to get letters like this from doctors - they don't usually give you such respect.

USEFUL(1): makes me understand more about myself; and as a memory aid.

049(1) Immensely pleased because two-thirds of my problem has been that over the years you get medical backstabbers that do not understand the situation and draw their own conclusions. It's nice to have it in writing and he was man enough to do it and considerate enough to send it to me. No backstabbing there - he was straight and prepared to put it in black and white.
USEFUL(1): I felt reassured that he'd really understood and it seemed that he'd grasped how I felt unbelievably well-picked up even the tiny bits. I hadn't realised quite how well he'd hit it all exactly smack on the nail, but the letter showed he had.

051(1) He seemed to have it all there - he'd taken in everything I'd told him. A nice letter and very good of him to take the trouble to write to me.

USEFUL(2): nice to have everything written down - I'd forgotten some of it but this brought it all back.

052(1) Just emphasises the interest he takes and it's always there to refer back to.

USEFUL(1): I've re-read it a couple of times since - it helps to know that he really did understand and I might be on the road to recovery. I haven't had the best medical attention in the past (to put it mildly) but this has made me feel much better about things and reassured me I'm not going mad.

\section{Comment}

On the whole patients liked getting the letter. They felt it showed respect and in some cases it raised the patient's self-esteem. They liked having it recorded 'in black and white' that their condition was extremely painful and disabling, and yet was not madness but a normal reaction to stress or an excess of normal emotion. A few patients were indifferent to the letter, but none was hostile to it or upset by it. No letters went astray or fell into the wrong hands. We were surprised how many patients showed the letters to friends and relatives. We think we are justified in concluding that only good can come of writing to the non-psychotic patient after a consultation.

The reactions of GPs were not systematically studied, but we had no adverse reaction and several said that it was useful to know exactly what the patient had been told. Some patients took the letter to their GPs and discussed it with them.

\section{Acknowledgements}

We are grateful to Mrs Gail Hawks, District Psychologist, Milton Keynes District Health Authority, who led the evaluation team; to Drs Aidan Power, Brendan Hourihan, Ashok Singh, Wayne King and S. Nagraj who wrote most of the letters; to Mrs Doreen Clarke who typed the letters and organised the appointments; and to the locally organised research scheme of Oxford Regional Health Authority who provided funding (Grant No. 87/11). 